\title{
TRABALHADORES COM EDUCAÇÃO SUPERIOR E AS TRANSFORMAÇÕES NO MUNDO DO TRABALHO
}

\author{
GRADUATES WORKERS AND TRANSFORMATIONS IN THE WORKFORCE \\ LOS TRABAJADORES DE LA EDUCACIÓN SUPERIOR Y LAS \\ TRANSFORMACIONES EN EL MUNDO DEL TRABAJO
}

\author{
Carolina Zuccarelli \\ Doutora em sociologia \\ Universidade Federal Fluminense - UFF. \\ Niterói, Rio de Janeiro - Brasil. \\ carolinazuccarelli@id.uff.br
}

\begin{abstract}
Resumo: O aumento da escolaridade ocupa espaço relevante nas formulações sobre oportunidades no mercado do trabalho e sobre as chances de mobilidade social. Este artigo tem como objetivo discutir em que medida a mudança no perfil educacional da força de trabalho de graduados com educação superior corresponde à alocação em grupos ocupacionais com demanda equivalente a esse nível de qualificação. Analisar essa relação tem relevância no momento de expansão significativa da educação terciária no Brasil e de profundas mudanças estruturais que afetam o funcionamento do mercado de trabalho. $\mathrm{O}$ texto examina as evidências dos últimos quarenta anos acerca das mudanças no perfil educacional da força de trabalho, levando em conta a relação entre anos de estudo e as oportunidades e/ou desigualdades do mercado de trabalho. A partir de dados produzidos pelo Instituto Brasileiro de Geografia e Estatística, o artigo mostra que, apesar do crescente número de trabalhadores com educação superior, a maior parte deste grupo não está inserida em função compatível com seu grau de qualificação, indicando um crescimento da taxa de graduados em ocupações que não requerem esse nível de escolaridade. Os resultados mostram ainda que o acesso ao ensino superior e ao mercado de trabalho brasileiro segue marcado por significativas desigualdades de gênero e cor/raça.
\end{abstract}

Palavras-Chave: educação superior; mercado de trabalho; desigualdade de gênero; desigualdade racial.

Abstract: The increase in years of study plays an important role in formulations about opportunities in the labor market and also about the chances of social mobility. This paper aims to discuss to what extent an increasing number of graduate workers corresponds to a greater allocation of the workforce in jobs that require higher education. The analysis of this relationship is particularly significant in the current scenario when substantial expansion of tertiary education and profound structural changes in the labor market are taking place. The text examines the changes in the educational profile of the workforce over the last forty years, taking into account the relationship between years of study and labor market opportunities and / or inequalities. Based on data produced by the Brazilian Institute of Geography and Statistics, the article shows that, despite the growing number of workers with higher education, most of this group is not employed in a job that is compatible with their qualification, indicating an increase in the graduation rate for posts that do not require this level of education. The results also show that access to higher education and the Brazilian labor market remain marked by significant gender and color / race inequalities.

Keywords: higher education; labor market; gender inequality; racial inequality.

Resumen: El aumento de la escolaridad ocupa un espacio relevante en las formulaciones sobre oportunidades en el mercado laboral y sobre las posibilidades de movilidad social. Este artículo tiene como objetivo discutir en qué medida el cambio en el perfil educativo de la población activa de los titulados con estudios superiores se corresponde con la asignación en grupos ocupacionales con demanda equivalente a este nivel de cualificación. El análisis de esta relación es relevante en el momento de una importante expansión de la educación terciaria en Brasil y de profundos cambios estructurales que afectan el funcionamiento del mercado laboral. El texto examina la evidencia de los últimos cuarenta años sobre los cambios en el perfil educativo de la población activa, teniendo en cuenta la relación entre los años de estudio y las oportunidades y / o desigualdades en el mercado laboral. Con base en datos producidos por el Instituto Brasileño de Geografía y Estadística, el artículo muestra que, a pesar del creciente número de trabajadores con educación superior, la mayoría de este grupo no se inserta en una función compatible con su grado de calificación, lo que indica un aumento en el calificar a los graduados en ocupaciones que no requieran este nivel de educación. Los resultados también muestran que el acceso a la educación superior y al mercado laboral brasileño sigue marcado por importantes desigualdades de género y color / raza.

Palabras Clave: educación universitária; mercado de trabajo; desigualdad de género; desigualdad racial.

Para citar - (ABNT NBR 6023:2018)

ZUCCARELLI, Carolina. Trabalhadores com educação superior e as transformações no mundo do trabalho. Eccos - Revista Científica, São Paulo, n. 57, p. 1-19, e10782, abr./jun. 2021. Disponível em: https://doi.org/10.5585/eccos.n57.10782. 


\section{Introdução}

Nos últimos 150 anos, as sociedades industrializadas têm conhecido um forte processo de ampliação dos sistemas de ensino. O Brasil, no entanto, apenas recentemente expandiu suas oportunidades educacionais, especialmente nos níveis médio e superior de escolarização. No mercado de trabalho, esse aumento refletiu em uma mudança substantiva na composição educacional da força de trabalho. Hoje, são aproximadamente $60 \%$ de ocupados com nível de instrução maior ou igual ao ensino médio, cenário bem diferente do encontrado na década de 1980, quando $13 \%$ dos trabalhadores tinham esse nível de educação (RIBEIRO e ARAGÃO, 2020).

As transformações no mundo do trabalho e a capacidade da estrutura de empregos de absorver o aumento do número de trabalhadores educados geraram uma série de estudos que discutiam a relação entre educação e trabalho, instituições que, em geral, são experienciadas em contextos organizacionais como o ensino formal e o mercado de trabalho ${ }^{1}$. Uma das principais teorias surgidas nesse contexto foi a do capital humano, na qual pessoas com mais escolaridade do que a exigida pela ocupação (overeducation) e pessoas com menor escolaridade do que a requerida pela ocupação (undereducation) seriam um fenômeno resultante do desencontro momentâneo entre indivíduos e mercado de trabalho. Hegemônica em meados do século XX, essa corrente de pensamento passou a ser revisitada por autores que observaram a persistência do desencontro entre ampliação das credenciais e estrutura do mercado de trabalho. Em debate, o fato de que o encontro entre qualificações e ocupações não é automático, obedecendo a diferentes lógicas e temporalidades.

Este artigo tem como objetivo avançar na discussão observando essa relação para os trabalhadores com diploma de educação superior no Brasil, debate que ganha relevância especialmente no contexto de expansão significativa da educação de nível terciário no país. Baseia-se em dados produzidos por pesquisadores do Observatório das Metrópoles, em pesquisa coordenada por Marcelo Gomes Ribeiro (IPPUR/UFRJ) sobre as transformações no mundo do trabalho ao longo de quatro décadas, na qual sistematizam dados dos censos demográficos de 1980, 1991, 2000 e 2010 e da Pesquisa Nacional por Amostra de Domicílios Contínua Anual de 2018, todos produzidos pelo Instituto Brasileiro de Geografia e Estatística (IBGE). ${ }^{1}$ Neste texto, a noção de educação se refere às credenciais obtidas pela passagem no sistema de ensino, enquanto trabalho se refere ao conjunto de ocupações
presentes no mercado de trabalho contemporâneo. 
O artigo está dividido em 03 seções, além da introdução e das considerações finais. A primeira apresenta os pressupostos analíticos de teorias que pensam a relação entre educação e trabalho, situada em torno de dois modelos, o meritocrático e o credencialista. A discussão é analisada no contexto brasileiro, com a apresentação de dados sobre as transformações no mundo do trabalho e na educação superior. O panorama é importante para a análise dos dados que é feita no capítulo seguinte, no qual é apresentada a metodologia utilizada no estudo e os resultados obtidos. A desigualdade no mercado de trabalho é analisada na seção posterior, quando questões como gênero e cor/raça são tratadas. A análise é baseada na intersecção entre os marcadores sociais de gênero e cor/raça.

As considerações finais levam em conta as transformações na composição educacional da força de trabalho e discutem a manutenção e produção das desigualdades no mercado de trabalho. Do ponto de vista macrossociológico, a dinâmica expressa a constituição da sociedade enquanto estrutura de oportunidades abertas ou fechadas aos indivíduos que a constituem. Já no nível microssociológico da análise, considera os valores e interesses que dão sentido e organizam a ação social, e que levam os trabalhadores a buscarem um diploma de educação superior, ainda que sua inserção em ocupações que demandem esse nível de ensino não seja garantida ${ }^{2}$.

\section{Teorias explicativas da relação entre formação e emprego}

A rápida expansão dos sistemas educacionais, notadamente em meados do século $\mathrm{XX}$, foi ponto de partida para uma série de discussões sobre os limites e possibilidades de absorção pelo mercado de trabalho da oferta crescente de pessoas com os mais diversos tipos de diploma. Esse debate tem sido interpretado, de maneira geral, dentro de perspectivas que tomam o mercado de trabalho como dimensão analítica, no qual tem destaque a teoria do capital humano, a do modelo de competição por emprego, teoria do filtro (screening theory), entre outras. Por outro lado, conforme cresce o desencontro entre qualificação e ocupação, ganha espaço teorias que sugerem pouco vínculo entre as duas dimensões, como a perspectiva credencialista. São dois modos divergentes de olhar para a mesma relação que podem ser agrupados em torno de dois modelos teórico-explicativos, o modelo meritocrático e o credencialista (BILLS, 2004).

\footnotetext{
${ }^{2}$ Frente às evidências de que a conclusão em um curso de graduação de nível superior é acompanhada pelo aumento das taxas de emprego e por retornos financeiros maiores (RIBEIRO e ARAGÃO, 2020), o movimento de busca por mais escolarização pode ser lido a partir dos valores e interesses que dão sentido e organizam a ação social, ainda que a inserção em ocupações que demandem esse nível de ensino não seja garantida.
} 
Do ponto de vista meritocrático, a associação entre educação e trabalho é sustentada pela racionalidade, pela produtividade social e por vantagens pessoais, tendo em vista a divisão técnica do trabalho. Nesse modelo, supõe-se uma associação positiva entre o que é ensinado na escola e aquilo que se necessita ou se utiliza na vida econômica, no mercado de trabalho, nas empresas, sendo as teorias funcionalistas e do capital humano modelos de explicação que ganham importância no período. A meritocracia é um princípio organizacional das sociedades capitalistas ocidentais contemporâneas, especialmente a partir do pós-guerra, quando o otimismo fez com que o conceito se tornasse dominante nas análises sociológicas. Mais especificamente, de acordo com Wallerstein (1995), o período 1945-68 teria sido o grande triunfo desse arranjo por conta do aumento nos níveis de emprego e da ampla expansão econômica que possibilitaram aumentar os gastos com educação.

Do ponto de vista credencialista, a escolarização formal leva ao sucesso socioeconômico não por causa das ferramentas e conhecimentos adquiridos, mas por conta da habilidade dos mais educados em controlar o acesso a posições de elite (fechamento social). Nessa visão, mais do que usar as credenciais para assegurar maior produtividade dos trabalhadores, empregadores fazem escolhas subjetivas no momento da contratação. A origem do argumento credencialista é associada ao trabalho de Weber, para quem a competição por credenciais foi determinante no sistema de estratificação moderno. Na visão do autor, inspirado na análise do sistema Confuciano $^{3}$, as credenciais educacionais são essencialmente construções político-culturais que pouco tem a ver com as demandas técnicas do mundo moderno (WEBER, 1978).

A teoria credencialista weberiana ganhou forte impulso com o trabalho de Collins (1971), para quem as evidências econômicas são claras e indicam nenhuma contribuição evidente da educação sobre o desenvolvimento econômico, apesar das previsões mais gerais. No esforço para construir uma teoria compreensiva da estratificação, o autor incorpora aspectos do funcionalismo como um poderoso incremento à teoria do conflito, analisando a relação educação e trabalho sem insistir numa sociabilidade pautada no conflito, dando lugar também à divisão técnica do trabalho. Isso é importante porque assume que a modernização e as mudanças técnicas que se impuseram no padrão de produção capitalista também contribuem com os formatos adquiridos pelo sistema de ensino. Seria esse um dos fatores para explicar a expansão educacional e o aumento das exigências educacionais ao longo do último século. No entanto, mais do que o domínio meritocrático de habilidades e competências, as disputas e o

${ }^{3}$ O Confucionismo ao qual se refere o autor é o resultado da burocracia patrimonial que se desenvolveu na China, onde mais do que o desenvolvimento de uma ciência ou de técnicas racionais, priorizava-se o pensamento de Confúcio enquanto base de formação de uma moral plutocrática-chinesa (WEBER, 1987). 
monopólio dos resultados ocupacionais são diretamente relacionados com acumulação de capital e exclusão social, transformando-se em um recurso artificial para monopolizar o acesso a determinadas ocupações.

O modelo credencialista permite analisar a expansão da educação superior em termos de manutenção de determinadas vantagens sociais, como a melhor inserção no mercado de trabalho de estudantes que cursam áreas específicas desse sistema. Trata-se de um tipo de estratificação que não se baseia nas análises de sua dimensão vertical, aquela que trata das desigualdades de acesso e da relação com a origem social dos estudantes, mas sim de sua dimensão horizontal, diferenças qualitativas num nível, curso, tipo institucional etc., que tem impactos na rentabilização de diploma no mercado de trabalho (MONT’ALVÃO, 2016).

Ao contrário do modelo segundo o qual o equilíbrio entre credenciais e ocupação se produz mediante o ajuste da oferta e demanda de qualificações, o modelo credencialista contempla a possibilidade de que exista um desajuste entre o nível de qualificação dos indivíduos e as demandas dos postos de trabalho, vantagens asseguradas pelo valor social dos diplomas que permitem explicar as desigualdades no mercado de trabalho em termos de ocupação.

Entre as duas perspectivas indicadas, como analisar a relação entre educação e trabalho no contexto nacional? Tomando como base a noção de que a organização do mundo do trabalho é intrinsecamente relacionada às dinâmicas e processos da ordem social, é possível indicar que a expansão dos sistemas educacionais e o número cada vez maior de trabalhadores qualificados mudam a própria natureza da organização da sociedade contemporânea. No Brasil, o aumento da escolaridade dos trabalhadores foi acompanhada de crescimento dos postos de trabalho para indivíduos mais qualificados, conforme veremos a seguir. Por outro lado, no que pese o aumento da qualificação da força de trabalho, a maior parte dos empregos está em setores de baixo conteúdo tecnológico, como agricultura, construção, transportes, serviços domésticos, entre outros (Tabela 01). São setores que fazem uso intenso do trabalho, em detrimento do uso de equipamentos e máquinas, um dado que indica o alto grau de desequilíbrio no mercado de trabalho no país, notadamente porque em setores de baixa tecnologia os salários são menores do que naqueles que fazem uso intenso de conteúdo tecnológico.

A próxima seção apresenta as mudanças na estrutura produtiva do país através da organização dos dados dos grupos ocupacionais desde 1980, da mesma forma que mostra a expansão da educação terciária, construindo um quadro de longo alcance que permitirá discutir 
a existência de ao menos três padrões de inserção ocupacional considerando a qualificação do trabalhador.

\subsection{Conjunturas do sistema educacional e do mercado de trabalho}

No período em análise neste trabalho (1980 a 2018), a população brasileira praticamente dobrou, passando de 119 milhões para 207 milhões de habitantes. A população economicamente ativa de 14 anos ou mais também teve crescimento expressivo, saindo de 42 milhões de pessoas em 1980 para chegar a 105 milhões em 2018 (RIBEIRO e ARAGÃO, 2020). O mesmo acontece com a população ocupada, que chega a 92 milhões de pessoas ao final da série, conforme mostra a Tabela 01 . O número de estudantes no ensino superior também segue a rota de crescimento observada no mercado de trabalho, em proporções menores, mas não menos vertiginosas, passando de pouco mais de um milhão e trezentos mil inscritos em 1980 para aproximadamente oito milhões e meio em 2018, conforme indica o Gráfico 01.

Para compreender as transformações no mundo do trabalho, os dados utilizados nesta pesquisa foram agrupados em torno de quatorze grupos ocupacionais, organizados de acordo com as características relacionadas ao processo de trabalho. A Tabela 01 apresenta dados do número de ocupados e a participação relativa entre 1980 e 2018 para os grupos ocupacionais estabelecidos. Através dela é possível identificar as mudanças na ordem social e econômica pelas quais o país vem passando, em especial o aumento absoluto da população ocupada em todos os grupos ocupacionais, com alguma oscilação entre as décadas intermediárias.

Tabela 1 - Número de pessoas e participação em percentual de acordo com os grupos ocupacionais - Brasil, 1980 a 2018

Continua

\begin{tabular}{|l|c|c|c|c|c|c|c|c|c|c|}
\hline \multirow{2}{*}{$\begin{array}{c}\text { Grupos } \\
\text { ocupacionais }\end{array}$} & \multicolumn{9}{|c|}{ Número de ocupados } & \multicolumn{5}{c|}{ Participação (\%) } \\
\cline { 2 - 12 } & $\mathbf{1 9 8 0}$ & $\mathbf{1 9 9 1}$ & $\mathbf{2 0 0 0}$ & $\mathbf{2 0 1 0}$ & $\mathbf{2 0 1 8}$ & $\mathbf{1 9 8 0}$ & $\mathbf{1 9 9 1}$ & $\mathbf{2 0 0 0}$ & $\mathbf{2 0 1 0}$ & $\mathbf{2 0 1 8}$ \\
\hline Empregadores & 1.078 .947 & 2.131 .704 & 1.897 .841 & 1.703 .131 & 4.484 .362 & 3 & 4 & 3 & 2 & 5 \\
\hline $\begin{array}{l}\text { Dirigentes e } \\
\text { servidores }\end{array}$ & 1.131 .580 & 1.787 .614 & 862.209 & 3.571 .961 & 3.578 .225 & 3 & 3 & 1 & 5 & 4 \\
\hline $\begin{array}{l}\text { Profissionais de } \\
\text { nível superior }\end{array}$ & 714.689 & 1.090 .756 & 2.251 .670 & 4.340 .563 & 5.302 .346 & 2 & 2 & 4 & 5 & 6 \\
\hline Professores & 1.081 .481 & 1.830 .643 & 2.406 .404 & 3.401 .503 & 4.056 .477 & 3 & 4 & 4 & 4 & 4 \\
\hline $\begin{array}{l}\text { Ocupações da seg. } \\
\text { pública e Forças } \\
\text { armadas }\end{array}$ & 492.134 & 679.944 & 757.538 & 357.722 & 1.038 .049 & 1 & 1 & 1 & 0 & 1 \\
\hline $\begin{array}{l}\text { Profissionais de } \\
\text { nível médio }\end{array}$ & 1.325 .110 & 1.989 .508 & 3.504 .172 & 4.898 .621 & 6.746 .837 & 3 & 4 & 6 & 6 & 7 \\
\hline & & & & & & & & & & \\
\hline $\begin{array}{l}\text { Trabalhadores do } \\
\text { apoio administrativo }\end{array}$ & 3.248 .298 & 4.324 .298 & 4.682 .302 & 6.251 .132 & 7.724 .210 & 8 & 8 & 8 & 8 & 8 \\
\hline
\end{tabular}




\begin{tabular}{|c|c|c|c|c|c|c|c|c|c|c|}
\hline \multicolumn{11}{|c|}{ Conclusão } \\
\hline $\begin{array}{l}\text { Trabalhadores do } \\
\text { comércio }\end{array}$ & 3.056 .320 & 5.190 .084 & 6.669 .080 & 7.887.899 & 11.144.397 & 7 & 10 & 11 & 10 & 12 \\
\hline $\begin{array}{l}\text { Trabalhadores da } \\
\text { prestação de } \\
\text { serviços }\end{array}$ & 4.099 .013 & 4.433.647 & 7.883 .131 & 10.516 .660 & 13.700 .545 & 10 & 9 & 13 & 13 & 15 \\
\hline $\begin{array}{l}\text { Operários da } \\
\text { indústria }\end{array}$ & 4.835 .760 & 5.834.539 & 6.862 .381 & 9.115.247 & 9.223 .605 & 12 & 11 & 11 & 11 & 10 \\
\hline $\begin{array}{l}\text { Operários da } \\
\text { construção civil }\end{array}$ & 3.788 .845 & 4.655 .291 & 4.660 .082 & 6.481 .241 & 6.650 .885 & 9 & 9 & 7 & 8 & 7 \\
\hline $\begin{array}{l}\text { Trabalhadores dos } \\
\text { transportes }\end{array}$ & 1.719 .710 & 2.254 .737 & 3.476 .865 & 3.706 .058 & 4.684.194 & 4 & 4 & 6 & 5 & 5 \\
\hline $\begin{array}{l}\text { Trabalhadores } \\
\text { domésticos }\end{array}$ & 2.472 .256 & 3.696 .257 & 4758296 & 4.958 .681 & 4.790 .738 & 6 & 7 & 8 & 6 & 5 \\
\hline $\begin{array}{l}\text { Trabalhadores } \\
\text { agrícolas }\end{array}$ & 12.054 .470 & 12.007.081 & 11.316.998 & 11.670 .141 & 7.952 .210 & 29 & 23 & 18 & 15 & 9 \\
\hline Outros & 212.325 & 415.527 & 666.011 & 964.797 & 1.228 .594 & 1 & 1 & 1 & 1 & 1 \\
\hline Total & 41.310 .938 & 52.321 .630 & 62.654 .980 & 79.825 .357 & 92.305 .674 & 100 & 100 & 100 & 100 & 100 \\
\hline
\end{tabular}

Fonte: Ribeiro e Aragão (2020)

A análise das mudanças nos grupos ocupacionais mostra que as ocupações relacionadas ao setor produtivo reduziram sua participação relativa no mundo do trabalho, especialmente aquelas relacionadas à indústria, à construção civil e, de maneira mais profunda, ao setor agrícola. De outro modo, houve aumento da participação de ocupações vinculadas ao setor de serviços, notadamente os trabalhadores do comércio e de serviços, que juntos somam quase $30 \%$ das ocupações listadas. Ao mesmo tempo, houve aumento absoluto e relativo dos profissionais de nível médio e superior, que atuam em diversos setores da atividade econômica. A dinâmica da população ocupada mostra que a redução dos trabalhadores agrícolas foi a mudança mais substantiva do período, junto com o aumento de ocupações no setor terciário.

O agrupamento dos trabalhadores levou em consideração a natureza comum das atividades exercidas e considerou dimensões como a distinção entre trabalho manual e não manual, natureza do trabalho e qualificação exigida ${ }^{4}$. Apenas para os empregadores foi utilizado o critério de posição na ocupação, justamente por apresentarem, em comum, a mesma posição em uma relação de trabalho. Dirigentes e supervisores são ocupações relacionadas a direção, gerência e supervisão de atividades econômicas dos setores público e privado. Profissionais de segurança pública e forças armadas são os indivíduos ocupados nas forças armadas, bombeiros, militares, polícia civil e militar, sendo profissionais da segurança privada analisados em trabalhadores de prestação de serviços, que inclui também serviços pessoais e de reparação. Profissionais de nível médio são as ocupações técnicas que exigem nível médio de escolaridade, inclusive na área de saúde. Trabalhadores de apoio administrativo são secretários, escriturários

\footnotetext{
${ }^{4}$ Para mais informações, ver Ribeiro e Aragão (2020), especialmente o anexo metodológico, páginas 600 a 635
} 
e ocupações de atendimento ao público. Em trabalhadores do comércio encontramos os que vendem mercadorias em comércio formal ou ambulante. Operários da indústria são trabalhadores manuais que atuam na indústria extrativa ou de transformação. Ainda como trabalhadores não manuais encontramos os operários da construção civil. Trabalhadores dos transportes são aqueles que atuam tanto no transporte de passageiros quanto no de mercadorias. Trabalhadores domésticos, governantas e mordomos são agrupados em trabalhadores domésticas, enquanto os trabalhadores agrícolas, pecuários e florestais estão no grupo trabalhadores agrícolas. Os professores agrupam profissionais da educação básica e superior, grupo que, em sua maioria, tem a exigência do diploma de nível superior. Profissionais de nível superior é o grupo por excelência que exige nível superior de escolaridade para seu exercício.

Esta forma de qualificação não se baseia na escolaridade exigida pelo posto de trabalho, mas abre caminhos para analisar as diferenças nas condições de trabalho, considerando a situação de informalidade, contribuição para a previdência, remuneração, características socioeconômicas, como escolaridade, cor/raça e sexo, entre outros. Também permite observar a dinâmica da mudança social ao longo do tempo, o que, em diálogo com mudanças estruturais do sistema educacional, coloca-se como exercício fundamental na compreensão da relação entre educação e transformações no mundo do trabalho.

Da mesma maneira como acontece no mundo do trabalho, são significativas as mudanças no setor educacional, que incluem uma progressiva expansão das oportunidades de acesso e permanência na educação de nível básico, universalização do acesso ao primeiro segmento do ensino fundamental e ampliação dos índices de conclusão nas etapas seguintes (SENKEVICS e CARVALHO, 2020). O aumento da progressão educacional teve como uma de suas consequências a ampliação da demanda pela expansão do sistema de ensino, pressionando os portões de acesso para segmentos mais elevados da progressão educacional. $\mathrm{Na}$ educação superior, o fenômeno acontece especialmente a partir do fim do século XX, conforme indica o gráfico abaixo. 
Gráfico 1 - Número de matrículas no Ensino Superior - Brasil, 1980 a 2018

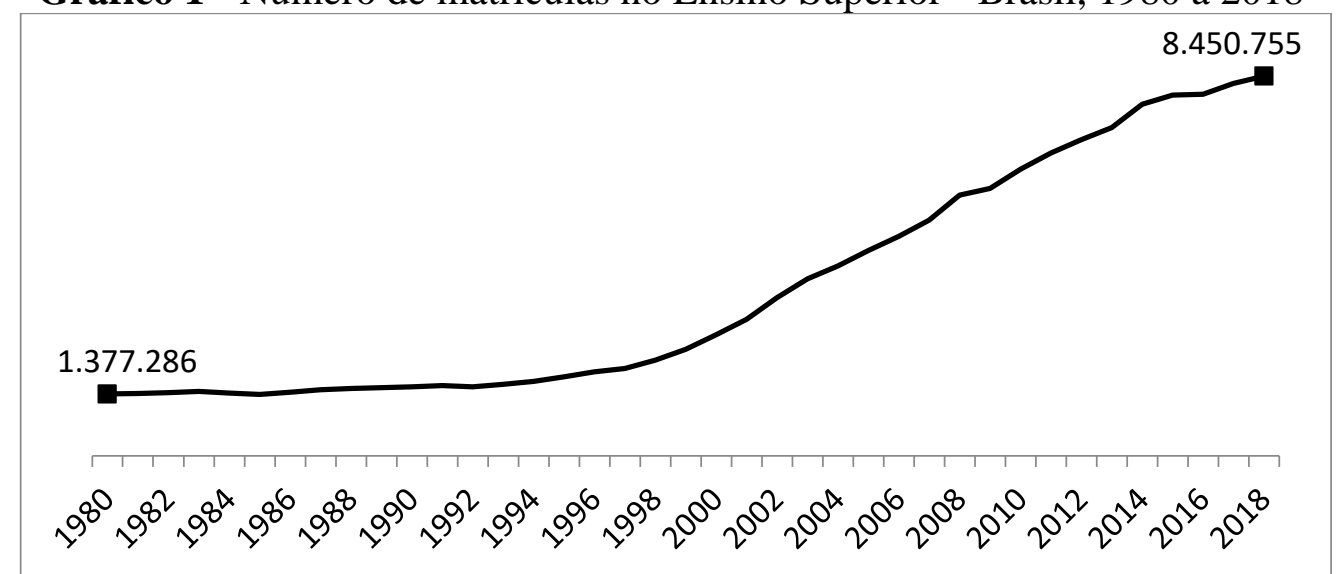

Fonte: Censo da Educação Superior (Inep/MEC), 1980 a 2018 - Elaboração da autora

Após uma década de estagnação da oferta de educação terciária no país, foi uma série de mudanças no ambiente econômico, político e social que deu fôlego a retomada da expansão das matrículas a partir de meados da década de $1990^{5}$, especialmente pela estratégia de estimular a oferta de vagas por meio das instituições privadas, seguida de uma flexibilização na oferta de cursos, que possibilitou, para além do convencional bacharelado de quatro anos, cursos tecnológicos e a distância. Além disso, políticas educacionais como o Prouni, Reuni e Fies foram fundamentais para a indução do crescimento do setor e para a mudança do perfil social de seus estudantes. Do ponto de vista da democratização do acesso, as instituições passaram a contar cada vez mais com estudantes de quintos mais pobres da distribuição de renda, ainda que estejam sub-representados (SENKEVICS, 2021). Também houve um aumento expressivo da presença de mulheres, negros e indígenas, em um rearranjo das desigualdades de acesso que desloca a discussão para o que a bibliografia tem chamado de desigualdades horizontais (MONT'ALVÃO, 2016), ou desigualdades efetivamente mantidas (LUCAS, 2001), que se dão nas diferenças de trajetórias considerando a área de conhecimento, modalidade do curso, categoria administrativa das instituições, entre outras.

Em números absolutos, a ampliação do acesso ao ensino superior foi tamanha que permitiu a transição de um sistema de elite para um sistema de massas ${ }^{6}$. Mesmo assim, o país apresenta um dos mais baixos percentuais de adultos de 25 a 34 anos de idade com escolaridade de nível superior quando comparado com países da Organização para a Cooperação e

\footnotetext{
${ }^{5}$ Antes disso, de maneira tardia em comparação com países da América Latina, a primeira grande expansão do ensino superior aconteceu na década de 1960 (SAMPAIO, 2000). Ao final desse processo, o número de matrículas atingiu a marca de aproximadamente 1,4 milhão de estudantes, mas ainda nos colocava distante de um sistema de massa (TROW, 1973). Na verdade, ainda estávamos diante de um sistema de elite na medida em que apenas $5,8 \%$ dos jovens entre 18 e 25 anos de idade estavam cobertos pela educação terciária (SENKEVICS, 2021).

${ }^{6}$ Tendo como referência os Estados Unidos, Trow (1973) estabeleceu três estágios de expansão do ensino superior: i. sistema de elite, com taxa de escolarização de até $15 \%$ da população na idade esperada; ii. sistema de massa, quando a taxa fica entre 15 e $50 \%$ da população; iii. e sistema universal, quando ultrapassa $50 \%$. No Brasil, a taxa é de $21 \%$ para o ano de 2019 (OCDE, 2020).
} 
Desenvolvimento Econômico (OECD), com a proporção de 21\%, à frente apenas da China, Indonésia, Índia e África do Sul (OECD, 2020). Somos também um país de elevadas desigualdades sociais, aprofundadas quando se trata de mulheres e negros, expressas tanto nas diferenças de acesso à melhores oportunidades educacionais, quanto nas ocupações no mercado de trabalho, discussão estabelecida na próxima seção.

\section{Desencontro entre escolaridade e ocupação}

O desencontro entre escolaridade e ocupação foi explorado por uma extensa literatura que trata dos trabalhadores com ensino superior nos países europeus e nos Estados Unidos, onde estima-se em torno de $30 \%$ a $40 \%$ o percentual de overeducation entre esses trabalhadores ${ }^{7}$. No Brasil, de acordo com Reis e Machado (2016), aproximadamente dois terços dos profissionais de nível superior estavam em postos de trabalho não relacionados à sua área de formação. A dinâmica do aumento de trabalhadores com ensino superior em ocupações para as quais não há exigência de elevados níveis de qualificação é expressa na tabela abaixo, que mostra o significativo incremento educacional da força de trabalho ao longo dos últimos quarenta anos.

Tabela 2 - Percentual de ocupados com superior completo de acordo com os grupos ocupacionais - Brasil, 1980 a 2018

\begin{tabular}{|l|c|c|c|c|c|}
\hline \multicolumn{1}{|c|}{ Grupos ocupacionais } & \multicolumn{5}{c|}{ Superior completo } \\
\cline { 2 - 7 } & $\mathbf{1 9 8 0}$ & $\mathbf{1 9 9 1}$ & $\mathbf{2 0 0 0}$ & $\mathbf{2 0 1 0}$ & $\mathbf{2 0 1 8}$ \\
\hline Empregadores & 10 & 16 & 25 & 33 & 35 \\
\hline Dirigentes e servidores & 3 & 6 & 7 & 13 & 20 \\
\hline Profissionais de nível superior & 75 & 85 & 67 & 72 & 94 \\
\hline Professores & 34 & 42 & 30 & 66 & 66 \\
\hline Ocupações da seg. pública e Forças armadas & 4 & 7 & 9 & 21 & 39 \\
\hline Profissionais de nível médio & 7 & 13 & 12 & 19 & 26 \\
\hline Trabalhadores do apoio administrativo & 2 & 4 & 6 & 10 & 17 \\
\hline Trabalhadores do comércio & 1 & 2 & 3 & 5 & 10 \\
\hline Trabalhadores da prestação de serviços & 2 & 4 & 6 & 10 & 17 \\
\hline Operários da indústria & 3 & 6 & 8 & 13 & 20 \\
\hline Operários da construção civil & 0 & 1 & 0 & 1 & 1 \\
\hline Trabalhadores dos transportes & 0 & 1 & 1 & 2 & 5 \\
\hline Trabalhadores domésticos & 1 & 1 & 1 & 1 & 1 \\
\hline Trabalhadores agrícolas & 0 & 1 & 1 & 2 & 3 \\
\hline Total & 100 & 100 & 100 & 100 & 100 \\
\hline
\end{tabular}

Fonte: Ribeiro e Aragão (2020). Elaboração da autora.

\footnotetext{
${ }^{7}$ Cohn e Kahn (1995), Sloane et al. (1999); Dolton e Vignoles (2000); Green et al. (2000); Carroll e Tani (2013).
} 
Dois grupos ocupacionais têm aumento expressivo de ocupados com ensino superior: os professores e as ocupações da segurança pública e forças armadas. No primeiro caso, foi fundamental para o fenômeno a exigência posta pela Lei de Diretrizes e Bases de 1996 para que a formação de docentes para atuação na educação básica se desse nesse nível de ensino, em cursos de licenciatura plena. A exceção é a formação para atuação na educação infantil e cinco primeiros anos do ensino fundamental, que ainda pode ser feita na modalidade normal, de nível médio, ainda que muitos docentes desse segmento tenham diploma de ensino superior (ZUCCARELLI, 2015). Os efeitos da lei, entre outros, fizeram com que o percentual de diplomados praticamente dobrasse no período analisado, saindo de 34\% em 1980 e chegando a $66 \%$ em 2018. O outro destaque é o grupo ocupacional formado pelas ocupações da segurança pública e forças armadas, que apresenta crescimento substantivo, saindo de 4\% em 1980 para chegar a 39\% em 2018, sendo uma das razões indicadas a alteração da exigência de escolaridade mínima para ingresso em algumas das carreiras que compõem o grupo, como acontece com os concursos para a polícia federal, que desde 2009 exige diploma de ensino superior para inscrição no processo seletivo (PEGORARO, 2020). Nos dois grupos ocupacionais, excetuando algumas categorias, estamos diante de ocupações que requerem o diploma de ensino superior para seu exercício.

Do mesmo modo, os profissionais de nível superior conformam o grupo ocupacional no qual o requisito é exatamente a titulação na educação terciária. Nesse caso, o crescimento foi menos expressivo porque já saiu de patamares mais altos de qualificação em comparação com os demais grupos, ainda que a mudança seja expressiva no período em questão. Trata-se do grupo que reúne o maior número de diplomados com ensino superior, com um percentual de $94 \%$ em 2018.

Os empregadores compõem o quarto grupo ocupacional com maior concentração de ocupados com ensino superior. Constituem-se por um grupo majoritariamente composto por homens brancos, de faixa etária elevada, com nível de escolaridade mais alta do que a população ocupada de modo geral (PASTERNAK, 2020). Não se trata de uma atividade que requer educação superior, mas que, de outro modo, agrupa 35\% de ocupados com esse nível de ensino.

Da mesma forma temos os profissionais de nível médio, grupo que formalmente não necessita de diploma de nível superior, mas que agrupava, em 2018, 26\% de trabalhadores com esse nível de qualificação. Ocupam uma posição intermediária no mercado de trabalho e que vem passando por um processo de intensificação da precarização das condições de trabalho que faz com que, por exemplo, o rendimento médio do grupo, significativamente superior ao da 
média da população ocupada em 1980, se aproxime do valor médio geral (FERREIRA e RAITANO, 2020).

A expansão da educação terciária segue mudando o perfil dos grupos ocupacionais para os quais não há exigência desse nível de qualificação, como os dirigentes e servidores, operários da indústria, do apoio administrativo, prestação de serviços e comércio. Esses grupos ocupacionais compõem uma faixa de ocupação que sai de patamares bastante baixos de graduados, em torno de 3 a $2 \%$ em 1980, e alcançam um aumento proporcional expressivo em 2018, agrupando em torno de 17 a 20\% de ocupados com nível superior.

De maneira menos expressiva, mas ainda com ganhos substantivos, os trabalhadores agrícolas e do transporte saem de um patamar muito baixo de qualificação e chegam em 2018 com percentual de 3\% e 5\%, respectivamente. São trabalhadores que se beneficiaram menos da recente expansão da educação terciária. Já os operários da construção civil e trabalhadores domésticos não foram beneficiados na medida em que permaneceram nos mesmos patamares de diplomados.

Ao analisar o dinamismo da elevação da escolaridade nos grupos educacionais, é possível apontar três movimentos: o primeiro, com expressivo crescimento do número de ocupados com educação terciária e alta proporção de graduados ao final do período analisado. Nesse grupo estão profissionais de nível superior, professores e, em menor proporção, ocupações da segurança pública e forças armadas e empregadores. É o grupo que, formalmente, apresenta maiores exigências de escolaridade. O segundo movimento inverte um dos sinais da equação acima, uma vez que é também expressivo o crescimento do número de ocupados com educação terciária, mas que, de outro modo, ainda apresenta baixa proporção de graduados ao final do período analisado. Esse grupo é composto pelos profissionais de nível médio, dirigentes e servidores, operários da indústria, trabalhadores do apoio administrativo, do comércio e da prestação de serviços. O terceiro grupo é formado pelos trabalhadores agrícolas e do transporte, formalmente aqueles com menor exigência de qualificação, refletido nos baixos níveis de ocupados com nível superior. Já os operários da construção civil e trabalhadores domésticos permanecem estagnados na dinâmica de expansão apresentada nos demais grupos e, por isso, não se enquadram no processo identificado de expansão das credenciais educacionais nos demais grupos ocupacionais.

O aumento de ocupados com nível superior nos grupos ocupacionais é explicado, em parte, pela expansão das credenciais nesse nível de ensino e, em menor grau, pelo aumento da participação das ocupações que demandam ensino superior que, em 1980, representavam 2\% 
do total e, em 2018, 6\% do conjunto dos trabalhadores ocupados. Por outro lado, ao mesmo tempo em que se observa uma ampliação de postos de trabalho para profissionais com nível superior, nota-se também uma ampliação de postos de trabalho que não requerem esse nível de escolaridade e que, de outro modo, absorvem trabalhadores diplomados na educação terciária.

Algumas hipóteses são levantadas para tratar desse desencontro, conforme visto na discussão sobre os modelos meritocráticos e credencialistas. No primeiro caso, o desajuste momentâneo seria compensado com a melhora do contexto econômico, quando o mercado seria capaz de gerar postos de trabalho suficientes para absorver os indivíduos mais escolarizados. No segundo caso, disputas e o monopólio dos resultados ocupacionais seriam diretamente relacionados com acumulação de capital e exclusão social, sem resultados práticos para o desenvolvimento econômico, mas fundamentais para organizar a estratificação social. A estrutura ocupacional brasileira se aproxima, de uma lado, do modelo credencialista, na medida em que a ampliação do número de trabalhadores com educação superior não se traduz em aumento substantivo de postos de trabalho com essa demanda de qualificação, mesmo em períodos de crescimento econômico. Por outro lado, uma vez que aumentam os postos de trabalho para trabalhadores mais qualificados, se aproxima do modelo meritocrático e da sua noção de expansão econômica, tendo em vista o aumento do nível educacional dos trabalhadores.

Assim, é fundamental considerar que a expansão dos sistemas educacionais e o número cada vez maior de trabalhadores qualificados mudaram e seguem mudando a forma de organização da sociedade contemporânea, tanto no que diz respeito às mudanças na composição social da força de trabalho, quanto às transformações do mundo do trabalho. Uma terceira perspectiva teórica é posta na medida em que se observa que o aumento dos anos de estudo muda não apenas as possibilidades de inserção profissional, como produz e sustenta novos entendimentos e significados sobre a dinâmica social, com destaque para o mundo do trabalho.

No entanto, diante do cenário de crise econômica e política que assola o país desde 2015 , é provável que haja uma inflexão da trajetória de crescimento da educação terciária e de retração do crescimento de ocupações que fazem uso intenso de conteúdo tecnológico e que demandam alto nível de qualificação. Em cenários como esse, novos desafios são lançados na análise da relação entre educação e trabalho (MANCEBO, 2017; SANTOS e TAVARES, 2018).

Sendo fator determinante para acesso à melhores ocupações, com papel decisivo na estratificação social, o acesso à educação e às oportunidades no mercado de trabalho não acontece da mesma maneira para os diferentes grupos sociais. A próxima seção analisa as 
desigualdades na estrutura ocupacional e o efeito do desencontro entre escolaridade e ocupação para os grupos sociais que mais viram crescer sua participação na educação terciária, mulheres, pretos e pardos.

\section{Desigualdades sociais no mercado de trabalho}

Embora tenha havido um aumento na participação de mulheres, pretos e pardos nos diferentes níveis de ensino, a maior mudança nos últimos anos é a crescente participação das mulheres na educação superior, com avanços mais tímidos do ponto de vista racial (RIBEIRO e SCHEGEL, 2015). No mercado de trabalho, as mulheres também aumentaram sua participação na maior parte dos grupos ocupacionais, excetuando professores, onde apresentam uma leve queda da participação, e trabalhadores domésticos, que manteve praticamente o mesmo percentual da década de 1980, sendo este o grupo que reúne o maior número de trabalhadores do sexo feminino dentre os analisados.

Tabela 3 - Percentual de mulheres ocupadas com superior completo de acordo com os grupos ocupacionais - Brasil, 1980 a 2018

\begin{tabular}{|l|c|c|c|c|c|}
\hline \multirow{2}{*}{ Grupos ocupacionais } & \multicolumn{5}{c|}{ Feminino } \\
\cline { 2 - 6 } & $\mathbf{1 9 8 0}$ & $\mathbf{1 9 9 1}$ & $\mathbf{2 0 0 0}$ & $\mathbf{2 0 1 0}$ & $\mathbf{2 0 1 8}$ \\
\hline Empregadores & 11 & 17 & 26 & 33 & 31 \\
\hline Dirigentes e servidores & 27 & 32 & 38 & 42 & 44 \\
\hline Profissionais de nível superior & 31 & 40 & 49 & 48 & 53 \\
\hline Professores & 83 & 82 & 78 & 76 & 76 \\
\hline Ocupações da seg. pública e Forças armadas & 1 & 4 & 6 & 8 & 10 \\
\hline Profissionais de nível médio & 32 & 39 & 35 & 44 & 51 \\
\hline Trabalhadores do apoio administrativo & 24 & 29 & 36 & 41 & 43 \\
\hline Trabalhadores do comércio & 30 & 36 & 46 & 53 & 53 \\
\hline Trabalhadores da prestação de serviços & 24 & 29 & 36 & 41 & 43 \\
\hline Operários da indústria & 27 & 32 & 38 & 42 & 44 \\
\hline Operários da construção civil & 1 & 4 & 1 & 5 & 3 \\
\hline Trabalhadores dos transportes & 1 & 3 & 2 & 4 & 4 \\
\hline Trabalhadores domésticos & 95 & 91 & 93 & 93 & 94 \\
\hline Trabalhadores agrícolas & 9 & 12 & 18 & 27 & 18 \\
\hline Total & 100 & 100 & 100 & 100 & 100 \\
\hline Fonte: Ribeiro e Aragão (2020).
\end{tabular}

Fonte: Ribeiro e Aragão (2020). Elaboração da autora.

São inegáveis os ganhos obtidos pelas mulheres em termos de participação nas ocupações que requerem nível superior. Nos grupos ocupacionais de trabalhadores do comércio, profissionais de ensino superior, empregadores, entre outros, os ganhos são expressivos. Em menor proporção, as ocupações relacionadas aos transportes e à construção civil. No entanto, ainda há uma distância marcante entre os sexos, não apenas relativa aos diferenciais salariais, mas especialmente no acesso a diferentes ocupações. A desigualdade de 
gênero tipicamente tem sido examinada através de uma variedade de fatores que explicam os diferenciais de salários entre homens e mulheres, como educação e experiência profissional, por exemplo. Essa abordagem, enquanto fundamental para demonstrar a existência de profundas desigualdades, falha em capturar os mecanismos pelos quais a segregação de gênero e as normas associadas a ela estão fortemente atreladas à ordem econômica e social. Em geral, às mulheres são reservadas as ocupações de menor prestígio, com menor poder de comando e de progressão na carreira. As trabalhadoras domésticas se constituem o exemplo mais imediato da reserva de mercado que aprofunda as desigualdades de gênero, mas pode ser incluída também uma série de profissões relacionadas à esfera do cuidar, como secretárias, enfermeiras e auxiliares, profissionais da educação infantil, entre outras (TILLY, 1999; DAVIS, 2016; GONZALEZ, 2020).

O aumento da participação de negros entre os trabalhadores ocupados também foi expressivo ao longo das últimas quatro décadas ${ }^{8}$, mas eles seguem sub-representados em ocupações de maior prestígio e retorno salarial, como no grupo ocupacional de trabalhadores de nível superior.

Tabela 4 - Percentual de pretos e pardos ocupados com superior completo de acordo com os grupos ocupacionais - Brasil, 1980 a 2018

\begin{tabular}{|l|c|c|c|c|c|}
\hline \multicolumn{1}{|c|}{ Grupos ocupacionais } & \multicolumn{5}{c|}{ Pretos e pardos } \\
\cline { 2 - 6 } & $\mathbf{1 9 8 0}$ & $\mathbf{1 9 9 1}$ & $\mathbf{2 0 0 0}$ & $\mathbf{2 0 1 0}$ & $\mathbf{2 0 1 8}$ \\
\hline Empregadores & 18 & 23 & 18 & 22 & 34 \\
\hline Dirigentes e servidores & 43 & 46 & 43 & 49 & 54 \\
\hline Profissionais de nível superior & 12 & 17 & 19 & 24 & 30 \\
\hline Professores & 19 & 29 & 30 & 38 & 35 \\
\hline Ocupações da seg. pública e Forças armadas & 38 & 43 & 41 & 47 & 55 \\
\hline Profissionais de nível médio & 27 & 33 & 32 & 41 & 49 \\
\hline Trabalhadores do apoio administrativo & 45 & 47 & 43 & 48 & 54 \\
\hline Trabalhadores do comércio & 35 & 42 & 44 & 46 & 55 \\
\hline Trabalhadores da prestação de serviços & 45 & 47 & 43 & 49 & 54 \\
\hline Operários da indústria & 43 & 46 & 43 & 49 & 54 \\
\hline Operários da construção civil & 71 & 59 & 58 & 65 & 68 \\
\hline Trabalhadores dos transportes & 38 & 43 & 44 & 48 & 56 \\
\hline Trabalhadores domésticos & 60 & 63 & 65 & 64 & 67 \\
\hline Trabalhadores agrícolas & 54 & 58 & 54 & 58 & 67 \\
\hline Total & 100 & 100 & 100 & 100 & 100 \\
\hline
\end{tabular}

Fonte: Ribeiro e Aragão (2020). Elaboração da autora.

Vale notar que, quando conseguem completar o ensino superior, pretos e pardos continuam em ocupações com menor exigência de qualificação do que brancos. Ribeiro e

\footnotetext{
${ }^{8}$ Especialmente no que diz respeito a dimensão racial, é preciso ponderar as mudanças observadas na autoidentificação de pretos e pardos às pesquisas do IBGE, que cresce na medida em que aumenta a consciência social da questão racial na sociedade brasileira (PETRUCCELLI e SABOIA, 2013),
} 
Schlegel (2015) mostram que o aumento da participação de negros no ensino superior não representou acesso igual a todas as carreiras universitárias, sendo mais intensa em áreas menos valorizadas pelo mercado de trabalho. O resultado, em termos de remuneração, mostra que a distância entre rendimentos de negros e brancos aumenta conforme o prestígio social do grupo ocupacional e que o rendimento das pessoas negras se aproxima do de pessoas brancas em grupos de menor prestígio social, onde negros são maioria. Além disso, o grau de formalização de pessoas negras é menor em praticamente todos os grupos ocupacionais (RIBEIRO e ARAGÃO, 2020).

No que pese os avanços observados, o acesso ao ensino superior e ao mercado de trabalho brasileiro segue marcado por significativas desigualdades de gênero e cor/raça. Mais especificamente, mulheres negras é o grupo que sofre com maior acúmulo de desvantagens socioeconômicas. A discriminação salarial e ocupacional as atinge mais fortemente do que qualquer outro grupo. Nesse cenário, abordagens que levam em conta as intersecções entre as discriminações de gênero e raça são fundamentais para a compreensão das desigualdades no país.

\section{Considerações finais}

Neste artigo vimos que, apesar da crença de que uma sociedade escolarizada é fator propulsor do crescimento econômico, importantes questões são postas quando se trata da relação entre educação e trabalho. Em meados do século XX, as teorias estruturaisfuncionalistas mostravam que a expansão educacional teria potencial de incrementar o desenvolvimento técnico e produtivo no posto de trabalho. Como resposta a hegemonia do período, surgiram novas teorias que buscavam minimizar a relação direta entre ferramentas educacionais, produtividade econômica e inserção no mercado de trabalho, mostrando que as demandas ocupacionais são menos relacionadas ao aprendizado de ferramentas concretas do que com disposições culturais para o preenchimento de determinadas posições. A partir das duas perspectivas indicadas, o artigo se propôs a analisar a relação entre educação e trabalho no Brasil contemporâneo.

Em primeiro lugar, a expansão do sistema de ensino e, mais especificamente, da educação superior, teve como uma de suas consequências o aumento da escolaridade do trabalhador. Ainda que em baixa proporção quando comparado com países da Europa e América Latina, o número de profissionais com diploma de ensino superior em ocupações que não demandam esse nível de qualificação cresceu no período, o que significa que, a despeito da 
expansão das credenciais, a estrutura de empregos não absorveu da mesma maneira os novos diplomados. Por outro lado, a expansão da escolaridade dos trabalhadores foi acompanhada de aumento dos postos de trabalho para indivíduos mais qualificados, notadamente no grupo ocupacional de profissionais de nível superior, importante indício de que a expansão da educação e as mudanças na força de trabalho não são tão desconectadas como previa o modelo teórico credencialista. Do mesmo modo, a expansão da escolaridade em ocupações que exigem menor nível de competência mostra falhas nas teorias agrupadas em torno do modelo meritocrático.

Um segundo ponto mostrou as interações entre os marcadores sociais de gênero e raça para analisar as mudanças na força de trabalho. Vimos que houve um aumento significativo da participação de mulheres e negros, ainda que sigam sub-representados em ocupações de maior prestígio. A dinâmica apresentada no processo de aumento da escolaridade e alocação nas ocupações expressa a constituição da sociedade enquanto estrutura de oportunidades abertas ou fechadas aos indivíduos que a constituem. As desigualdades de gênero e de raça, em sistemas fechados como o brasileiro, seguem representando um forte obstáculo para a diminuição das desigualdades no país.

Ainda é necessário, no entanto, avançar no modelo de transição entre sistemas educacionais e mercado de trabalho no Brasil, sobretudo porque o desencontro entre formação e ocupação para trabalhadores graduados coloca questões importantes tendo em vista o potencial de crescimento da educação superior. Cabe questionar, e será uma oportunidade para discutir as diversas teorias acerca da relação entre educação e trabalho, a capacidade do mercado de trabalho brasileiro em absorver, nos próximos anos, trabalhadores graduados, em ocupações que requerem ensino superior. Por outro lado, com a crise política e econômica no país que se aprofunda desde 2015, as tendências observadas devem sofrer uma inflexão, colocando novas questões para pesquisadores interessados na relação entre qualificação dos trabalhadores e as mudanças no mundo do trabalho.

\section{Referências}

BILLS, D. The sociology of education and work. Oxford, Blackwell Publishing, 2004.

CARROLL, D.; MASSIMILIANO, T. Job search as a determinant of graduate overeducation: Evidence from Australia. IZA Discussion Paper n. 7202, February 2013.

COHN, E; KAHN, S. The Wage Effects of Overschooling Revisited. Labour Economics, 1995. 
COLLINS, R. Functional and Conflict Theories of Educational Stratification. American Sociological Review, Vol. 36, No. 6.,1971.

DAVIS, A. Mulheres, raça e classe. São Paulo: Boitempo, 2016.

DOLTON, P.; A. VIGNOLES. The incidence and effects of overeducation in the U.K. graduate labour market. Economics of Education Review, p.179-198, 2000.

GONZALES, L. E a trabalhadora negra, cumé que fica? In: RIOS, Flavia.; LIMA, Márcia (org.) Por um feminismo afro-latino- americano. Rio de Janeiro: Zahar, 2020.

GREEN, F., ASHTON, D., BURCHELL, B., DAVIES, B. and FELSTEAD, A. Are British Workers Becoming More Skilled? in Borghans, L. and A. de Grip, (eds.), The Overeducated Worker? The Economics of Skill Utilization, Edward Elgar: Cheltenham, 2000.

FERREIRA, P. G. M.; RAITANO, F. C. Profissionais de nível médio: entre o fazer prático e o conhecimento abstrato. In: RIBEIRO, M. G.; ARAGÃO, T. A. (org.). Transformações no mundo do trabalho. Análise de grupos ocupacionais no Brasil Metropolitano e Não Metropolitano em quatro décadas. Rio de Janeiro: Letra Capital, 2020.

LUCAS, S. Effectively maintained inequality: education transitions, track mobility, and social background effects. American Journal of Sociology, v. 106, n. 6. May, 2001.

MANCEBO, D. Crise político-econômica no Brasil: breve análise da educação superior. Educ. Soc., Campinas, v. 38, nº. 141, p.875-892, 2017

MONT'ALVÃO, A. A dimensão vertical e horizontal da estratificação educacional. Teoria e Cultura, v. 11, n.1, jan./jun., 2016

ORGANISATION FOR ECONOMIC CO-OPERATION AND DEVELOPMENT (OECD). Education at a glance 2020: OECD indicators. Paris: OECD Publishing, 2020

PASTERNAK, S. Empregadores: empresários ou trabalhadores? In: RIBEIRO, M. G.; ARAGÃO, T. A. (org.). Transformações no mundo do trabalho. Análise de grupos ocupacionais no Brasil Metropolitano e Não Metropolitano em quatro décadas. Rio de Janeiro: Letra Capital, 2020.

PEGORARO, G. O perfil social dos policiais rodoviários federais. 2020. 67f. Trabalho de conclusão de curso (licenciatura em ciências sociais) - Universidade Federal Fluminense, Niterói, 2020.

PETRUCCELLI, J. L.; SABOIA, A. L. (org.). Caraceterísticas étnico-raciais da população. Estudo e Análises, n. 2, 2013.

REIS, M. C.; MACHADO, D. C. Uma análise dos rendimentos do trabalho entre indivíduos com ensino superior no Brasil. Economia Aplicada, vol. 20, n.4, 2016. 
RIBEIRO, C. A. C.; SCHLEGEL, R. . Estratificação horizontal da educação superior no Brasil (1960 a 2010). In: Arretche, Marta (org.) Trajetórias das desigualdades: como o Brasil mudou nos últimos cinquenta anos. São Paulo: Editora Unesp, v. 1, 2015.

RIBEIRO, M. G.; ARAGÃO, T. A. Transformações no mundo do trabalho. Análise de grupos ocupacionais no Brasil Metropolitano e Não Metropolitano em quatro décadas. Rio de Janeiro: Letra Capital, 2020.

SAMPAIO, H. Ensino superior no Brasil - o setor privado. São Paulo: Fapesp/Hucitec, 2000.

SANTOS, E.; TAVARES, M. Economia política e educação. EccoS - Rev. Cient., São Paulo, n. 47 , set./dez. 2018

SENKEVICS, A. S.; CARVALHO, M. P. Novas e velhas barreiras à escolarização da juventude. Estudos Avançados, São Paulo, vol. 34, n. 99, 2020.

SENKEVICS, A. S. A expansão recente do ensino superior: cinco tendências de 1991 a 2020. Caderno de Estudos e Pesquisas em Políticas Educacionais, Brasília, vol. 3, n.4, 2021.

SLOANE, P. J.; BATTU, H.; SEAMAN, P. T. Overeducation, Undereducation and the British Labour Force. Applied Economics, November, 31(11), 1999.

TILLY, C. Durable inequality. London: University of California Press, 1999.

TROW, M. Problems in the transition from elite to mass higher education. Berkeley: Carnegie Commission on Higher Education, 1973.

ZUCCARELLI, C. Análise dos ingressantes no curso de pedagogia da UFRJ a partir de suas trajetórias no ensino médio. In: HONORATO, G; HERINGER, R.(Orgs.) Acesso e sucesso no ensino superior: uma sociologia dos estudantes. Rio de Janeiro: 7 Letras, 2015.

WALLERSTEIN, I. As agonias do liberalismo: As esperanças para o progresso. In: SADER,E. (ORG.). O mundo depois da queda. Rio de Janeiro: Paz e Terra, 1995.

WEBER, M. Economy and Society. Berkeley:University of California Press, 1978.

WEBER, M. Ensayos sobre sociología de la religión. Madrid: Taurus, 1987. 